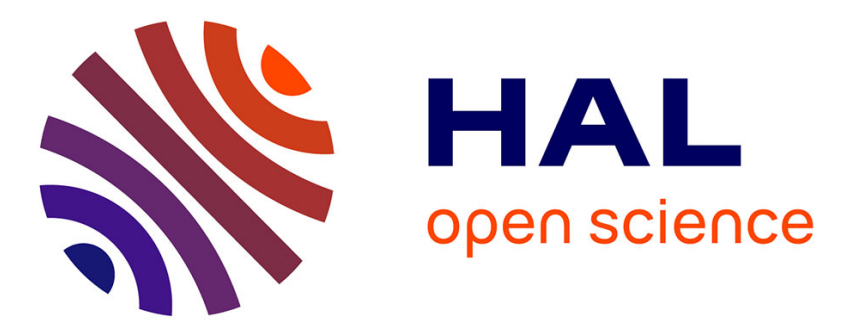

\title{
Exploring adaptations to climate change with stakeholders: a participatory method to design grassland-based farming systems
}

Marion Sautier, Mathilde Piquet, Michel Duru, Roger Martin-Clouaire

\section{- To cite this version:}

Marion Sautier, Mathilde Piquet, Michel Duru, Roger Martin-Clouaire. Exploring adaptations to climate change with stakeholders: a participatory method to design grassland-based farming systems. Journal of Environmental Management, 2017, 193, pp.541-550. 10.1016/j.jenvman.2017.02.050 . hal01607512

\section{HAL Id: hal-01607512 \\ https://hal.science/hal-01607512}

Submitted on 26 May 2020

HAL is a multi-disciplinary open access archive for the deposit and dissemination of scientific research documents, whether they are published or not. The documents may come from teaching and research institutions in France or abroad, or from public or private research centers.
L'archive ouverte pluridisciplinaire HAL, est destinée au dépôt et à la diffusion de documents scientifiques de niveau recherche, publiés ou non, émanant des établissements d'enseignement et de recherche français ou étrangers, des laboratoires publics ou privés.

\section{다(1)(2)}

Distributed under a Creative Commons Attribution - ShareAlikel 4.0 International 


\section{Exploring adaptations to climate change with stakeholders: A participatory method to design grassland-based...}

Article in Journal of Environmental Management · March 2017

DOI: 10.1016/j.jenvman.2017.02.050

CITATIONS

0

4 authors, including:
READS

32
Marion Sautier

École Nationale Vétérinaire, Agroalimentaire ...

14 PUBLICATIONS 27 CITATIONS

SEE PROFILE

\section{Roger Martin-Clouaire}

French National Institute for Agricultural Res...

90 PUBLICATIONS 1,047 CITATIONS

SEE PROFILE

\section{Michel Duru}

French National Institute for Agricultural Res...

17 PUBLICATIONS 42 CITATIONS

SEE PROFILE

Some of the authors of this publication are also working on these related projects: 
The final version of this article has been published in the Journal of Environmental Management, and is available online at http://dx.doi.org/10.1016/j.jenvman.2017.02.050.

\title{
Exploring adaptations to climate change with stakeholders: a participatory method to design grassland-based farming systems
}

\author{
Marion Sautier $^{\mathrm{a}, 1}$, Mathilde Piquet $^{\mathrm{a}, 2}$, Michel Duru $^{\mathrm{a}}$, Roger Martin-Clouaire $^{\mathrm{b}}$
}

\begin{abstract}
Research is expected to produce knowledge, methods and tools to enhance stakeholders' adaptive capacity by helping them to anticipate and cope with the effects of climate change at their own level. Farmers face substantial challenges from climate change, from changes in the average temperatures and the precipitation regime to an increased variability of weather conditions and the frequency of extreme events. Such changes can have dramatic consequences for many types of agricultural production systems such as grassland-based livestock systems for which climate change influences the seasonality and productivity of fodder production. We present a participatory design method called FARMORE (FARM-Oriented REdesign) that allows farmers to design and evaluate adaptations of livestock systems to future climatic conditions. It explicitly considers three climate features in the design and evaluation processes: climate change, climate variability and the limited predictability of weather. FARMORE consists of a sequence of three workshops for which a preexisting game-like platform was adapted. Various year-round forage production and animal feeding requirements must be assembled by participants with a computerized support system. In workshop 1 , farmers aim to produce a configuration that satisfies an average future weather scenario. They refine or revise the previous configuration by considering a sample of the between-year variability of weather in workshop 2. In workshop 3, they explicitly take the limited predictability of weather into account. We present the practical aspects of the method based on four case studies involving twelve farmers from Aveyron (France), and illustrate it through an in-depth description of one of these case studies with three dairy farmers. The case studies shows and discusses how workshop sequencing (1) supports a design process that progressively accommodates complexity of real management contexts by enlarging considerations of climate change to climate variability and low weather predictability, and (2) increases the credibility and salience of the design method. Further enhancements of the method are outlined, especially the selection of pertinent weather scenarios.
\end{abstract}

Keywords: climate variability; dairy cow; grassland; intermediary object; farm management; participatory

a: AGIR, Université de Toulouse, INRA, INPT, INP- EI PURPAN, 31320, Auzeville, France

b: MIAT, INRA, Université de Toulouse, Auzeville CS 52627, 31326, Castanet Tolosan, France

${ }^{1}$ Corresponding author

${ }^{2}$ Present address: ODG Pays du Domfrontais, 61700 Domfront, France

Marion Sautier

INRA, UMR 1248 AGIR, F-31326 Castanet-Tolosan, France

marion.sautier@gmail.com

+33561285031

Mathilde Piquet

mathilde.piquet@orange.fr

Michel Duru

michel.duru@inra.fr

Roger Martin-Clouaire

roger.martin-clouaire@inra.fr 


\section{Introduction}

Agricultural sustainability is facing substantial challenges from climate change. The variability of weather conditions and the frequency of extreme events are forecasted to increase along with changes in the mean of climatic variables (Seneviratne et al., 2012). Such changes can have dramatic consequences for many types of agricultural production systems such as grassland-based livestock systems for which climate change influences the seasonality and productivity of fodder production. Since climate change is a continuous process, responses based on current situations will likely become increasingly inappropriate over time. In this context, research is expected to produce knowledge, methods and tools to help farmers anticipate and cope with the effects of climate change on their systems.

Designing farming systems adapted to climate change should be conducted at the farm or enterprise scale to match the scale at which the farmer makes his/her decisions (Rodriguez et al., 2011). Methods that primarily rely on dynamic simulation models often fail to address this problem because of the complex relations between climatic, biophysical and management variables, which induce either oversimplification or loss of intelligibility and credibility of the models. Moreover, since adaptations are most often site-specific, it is necessary to develop a deep understanding of the system under study (Duru et al., 2015).

The design process must offer farmers the possibility to consider their own situations and use their knowledge and skills to generate salient, legitimate and credible responses (Cash et al., 2003). This could be facilitated through participatory workshops with scientists and farmers, since they constitute a privileged space for discussion and knowledge sharing, particularly around system adaptation to climate change (Bartels et al., 2013; Voinov and Bousquet, 2010). In participatory processes, participants are invited to cooperate in solving a problem by mobilizing their own experiences and skills in facilitated workshops. Basically, farmers, as managers of natural resources, have experiential knowledge, which is more focused and pragmatic than scientific knowledge and often supports a better understanding of system functioning and management risks (Fazey et al., 2006).

Existing methods to design farming systems are focused on gradual changes in mean climatic variables and, possibly, on risks related to extreme events. Although adaptation to climate change must include adaptation to climate variability (Smit et al., 2000), most current studies on farming system adaptation to climate change have been performed without considering climate variability (Estrada et al., 2011) and have probably underestimated the full impacts of climate change (Thornton et al., 2014). In such methods climate is regarded through sets of scenarios, each conveying a contextual perspective over several decades (typically 30 years). Scenarios may also be communicated through a virtual average climatic year (e.g. Martin et al., 2011a) or a succession of a few years (e.g. Lamarque et al., 2013), since yearly scenarios are usually easier to understand (Lamarque et al., 2013). In addition, these methods fail to take into account the system management impact of the limited predictability of weather since they assume full knowledge of the weather over the temporal horizon of interest. Consequently, the system designed may lack robustness because it is not accompanied with fine-grained adaptations that could deal with peculiarities of a specific year and cope with a large enough range of weather-induced situations and operational conditions.

With awareness of the above deficiencies, we present a three-stage participatory method, called FARMORE (for FARM-Oriented REdesign) that enhances the creativity of participants in designing grassland-based systems adapted to new climatic conditions. The method is tailored to allow farmers to practically assess consequences of climate change on grassland-based livestock systems and immediately estimate the worth of adaptations generated. The entire process enables simultaneous communication about climate change and its consequences to farmers at the farm level and engages them in the adaptation process. It consists of a sequence of three workshops (W) for which we adapted a pre-existing game-like platform ("Forage Rummy" - Rami fourrager ${ }^{\circledR}$, Martin et al. (2011a)). Our design method has four original features: (1) it explicitly considers climate change, climate variability and the limited predictability of weather; (2) it breaks down the design effort into sequential steps, which is a way to keep the problem tractable, generate more robust solutions and increase the realism of the constraints considered in design process; (3) it uses dynamic simulation models to evaluate adaptation options in an innovative way, since no simulation is run during the design process, to avoid the black box effect, and (4) it considers the complexity of a livestock system in 
terms of the diversity of forage resources, animal herds and management options. This article focuses on the methodological aspects underlying our design method more than the designed systems that may be constructed with this method.

\section{FARMORE: a sequential participatory design method}

\subsection{The Forage Rummy background}

The method FARMORE draws on the use of a game-based design method called Forage Rummy (FR) (Martin et al., 2011a). FR aims to design livestock farming systems that are consistent with a selected combination of farmer's objectives (e.g. forage self-sufficiency) and production contexts (e.g. frequency and magnitude of extreme climatic events, doubling of fuel price). The design task takes place in a participatory workshop involving a group of farmers and one agent (extension agent or researcher) who acts as a facilitator. FR allows addressing complex issues at the farm level such as forage self-sufficiency, change in the grazing:cutting ratio of grasslands on the farm or climate extremes. As identified by the creators of the game, FR workshops benefit farmers and extension agents in different ways (Martin et al., 2011a; Piquet et al., 2013). Farmers can virtually test alternative land-use, livestock-management, feeding and forage-management policies. They can also assess the robustness of their system to a certain climatic or socioeconomic context. Extension agents can elicit farmer practices more easily than during an interview and then provide more relevant advice. It also helps extension agents in building trust with farmers. A list of selected materials to better understand FR (articles, video and game box) is provided in the supplementary material.

FR relies on a number of intermediary objects that put relevant pieces of scientific knowledge in a tractable form for the design task (Figure 1). They are:

- a temporally-structured game board that represents the farming system. The upper part of the board is dedicated to the farmland area (with "forage sticks"). The lower part represents feeding requirements and practices (animal cards and diet cards). The year is divided into 13 four-week periods.

- forage sticks, each describing a specific forage crop and its year-round management and productivity. Each stick indicates corresponding accessible forage yield in kilograms or tons per hectare and per four-week period across the calendar year for a given weather scenario (also called climatic year).

- animal cards, each with characteristics of a representative animal for each herd subgroup (e.g. breed, age) and the associated management practices (e.g. calving date, expected productivity level). Up to 3 herd subgroups can be represented.

- diet cards, each corresponding to a type of feed (e.g. grazed herbage). Participants use them to specify the type of diet assigned to one herd subgroup over a four-week period by selecting one or several diet cards (e.g. 100\% maize silage versus maize silage mixed with grazed herbage).

With the support of a facilitator, up to four farmers can collectively play FR, which consists of combining these objects to develop a virtual configuration of the farming system: land use (types of forage crops and grasslands with associated surface areas and management practices), herd subgroups (size, production target), and subgroup diets throughout the year in a given economic and climatic year. The consistency of the farming system (e.g. the ratio of forage supply to consumption, the technical feasibility) is assessed at any time during the game by participants' opinions and a forage supply-consumption balance model embedded in an evaluation spreadsheet. The evaluation spreadsheet summarizes the system's performance at both four-week and annual scales. Workload, social acceptability and economic performance of the system designed are discussed informally among participants. 


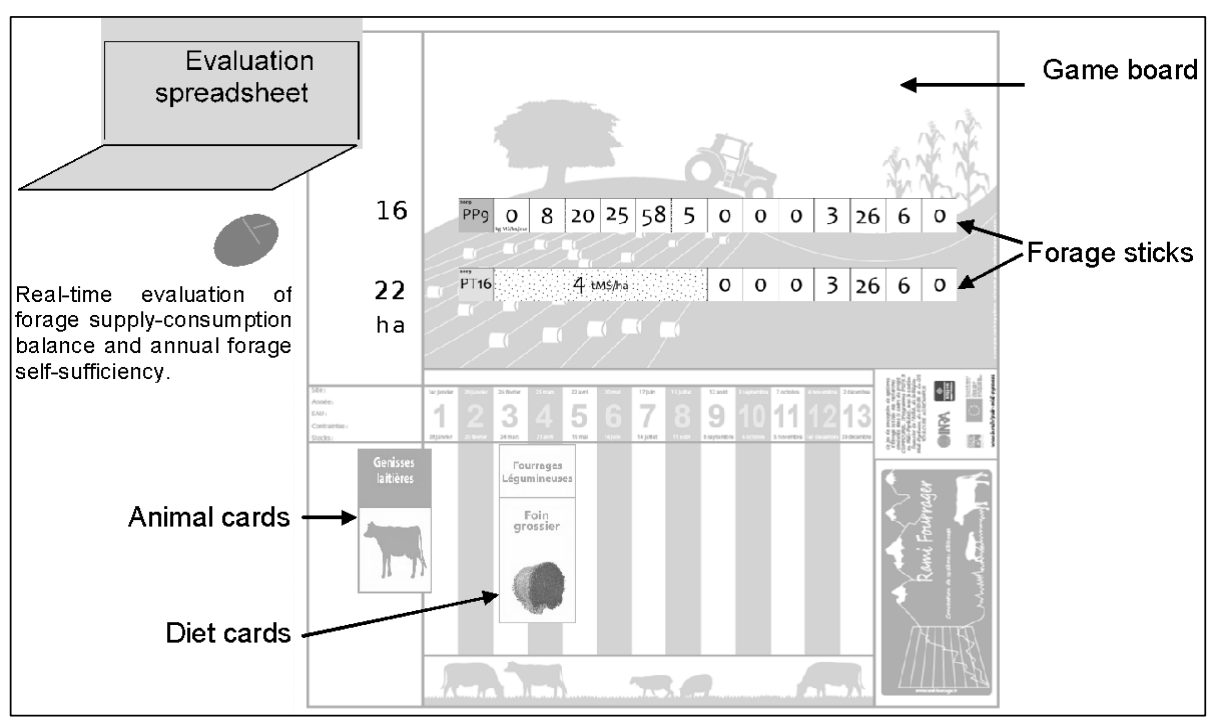

Figure 1: The Forage Rummy (Rami Fourrager ${ }^{\circledR}$ ) board game and the four elements used by players to design and evaluate a virtual livestock farm. Adapted from Piquet et al. (2013). Each of the elements is freely determined based on local parameters (soil, climate, farming practices, cultivated species, etc.).

\subsection{Sequential design}

The FARMORE method required modifications of certain aspects of the original FR to better represent climate variability. We structured our design method on a sequence of three workshops (W1 to W3), each using a modified version of the Forage Rummy and a chosen climate scenario. This way at least three well-chosen climatic years are studied, allowing participants to consider several climatic years. We changed the time step to one week and added the ability to explicitly represent the location of the grazing herd to allow for finer changes in grazing management than with the original FR. Adaptation of a grassland-based livestock farming system to climate variability and efficient grazing management mainly rely on weekly changes, such as in stocking rate, especially when herbage growth is high in spring. Finally, we added the ability to progressively reveal the weather scenario (e.g. by four-week periods) to force participants to manage risk and uncertainty when designing the farming system. An annotated photograph of the board game under these settings is provided in the supplementary material. The evaluation spreadsheet (in French) is available upon request.

Farmers deal with average climate change in W1, with an initial sample of future climate variability (a climatic year within a category of frequent years) in W2 and with the limited predictability of weather and a second sample of future climate variability (another climatic year) in W3. The features of the climatic situations considered in W2 and W3 are an open choice. The climatic situation considered in W2 is taken from a frequent climatic year, whereas that considered in W3 can be taken either from frequent or extreme climatic years. Choosing a frequent climatic year in W3 enables participants to evaluate whether the system is adapted to future climate under realistic management (incomplete information, irreversible decisions). Conversely, choosing an extreme year in W3 enables participants to evaluate the adaptive capacity of the system to cope with extreme climatic hazards under the same realistic management constraints. In either case, participants are informed about the nature (extreme or not) of the climatic year scenario by the end of the workshop. At the end of the three workshops, participants will have designed a farming system adapted to three weather scenarios of the future climate.

In W1, farmers aim to design a livestock system adapted to an average future climatic year for the studied period. First, they use the game for a well-known scenario to become familiar with its principles. Here, they have to design a farming system adapted to the current average climatic year (climatic reference situation). Only afterwards can the participants engage in designing a system adapted to an average future climatic year. They can change any component of the original livestock system. They decide if the strategy of the livestock system, such as production objectives, land use and the size of the system, needs to be revised. This workshop uses a classic FR setting: the entire climatic year is revealed at the beginning of the workshop, the temporal resolution is four weeks, and the on-farm location of animals is ignored. The evaluation spreadsheet displays information at both 
four-week and annual scales (Table 1). At the end of the workshop, participants would know how to play and should have an overall idea about future weather conditions under climate change, its consequences on forage resources at their local level and possible adaptations on a strategic level.

In W2, farmers aim to test and, if necessary, increase the robustness of the system designed in W1. Strategic choices (e.g. number of animals, land-use, hay stock at the beginning of the year) made in the system might be reconsidered. The purpose is to achieve a farming system that is adapted to a type of year considered frequent in a future climate. The main changes expected in the system concern tactical choices (e.g. turnout to grazing, area harvested). Participants address the following questions: "Does the original system still work in weather scenarios that are likely in the future? If not, what tactical adaptations can be made? Do strategic choices have to be reconsidered?" For this, the system must be represented more finely at the temporal and spatial level than it was in W1; FR is no longer adapted to this end. FARMORE relies on a reframed version of FR with the temporal resolution decreased to one week and in which herd movement between grasslands is explicitly considered, which makes it possible to calculate more accurately the forage available to feed animals. Here, the evaluation spreadsheet displays information at both one-week and annual scales. W2 allows participants to become familiar with FARMORE while reconsidering the system. By considering a frequent year of future climate conditions, participants enrich their representation of climate change and their knowledge of possible consequences on forage resources and of possible adaptations.

In W3, farmers aim to refine the system designed in the previous workshops and, if necessary, make it more adaptive to weather conditions as they occur. The workshop creates a realistic management situation, in which future weather has limited predictability, except for short time windows. The system is no longer designed but is tested under weather uncertainty. To achieve this, the climatic year is revealed progressively in four-week periods, and the system is examined each week. Estimates of the system's annual performance are displayed at the end of the workshop. The climatic year is not revealed in shorter periods to keep the workshop duration under two hours. Participants must consider actions that would make the system viable regardless of the weather in the next period. Only tactical adaptations are performed in this step. After W3, farmers will have tested the method, designed a system adapted to future average climate conditions, refined or reconsidered it under a frequent future climatic year and tested it under realistic management conditions (i.e. limited weather predictability, weekly decisions, herd movement). 
Table 1: Description of the sequential design process: objective, weather scenario and version of Forage Rummy used, type of adaptation discussed, and outputs and outcomes of each workshop

Workshop 1

\section{Change in trend}

Configuration of a balanced system

a. Average past climatic year

\section{Weather scenario}

Type of adaptation Strategic choices (goals, size, land use) b. Average future climatic year
Workshop 2

Future variability (sample 1)

Make system robust in the face of variability

Frequent climatic year of the future

Tactical adaptations (turnout date, diet, forage stock

$$
\text { size) }
$$

\section{Workshop 3}

Future variability (sample 2) and limited forecasting

Make system robust in the face of variability and short-term forecasts

Frequent or exceptional climatic year of the future

Strategic choices reconsidered if needed

Reframed

Reframed + limited predictability of weather

Version of Forage

Original

Week

Week

Design time-scale

Month

Grazing plots considered individually

Grazing plots considered individually

All grazing plots considered as a whole

Display of climate

scenario

For the entire year

For the entire year

Output

System adapted to average change

System adapted to average change and a sample of weather variability

Progressively, in four-week periods

System adapted to average change, two samples of weather variability and short-term weather forecast Successful and unsuccessful adaptation options Adaptation ideas to be tested

Outcomes

Participants put the method and the

facilitators to the test

Group building

Enriched representation of climate change, its

impacts and possible adaptations

Group building
Same as in Workshop $2+$

Discussions about risk management 


\section{$3 \quad$ Practical use of the method: an example}

We applied our method to four case studies (dairy or beef systems located in uplands or valleys) in Aveyron, France, with a total of twelve participating farmers (see Sautier, 2013). At the end of each workshop, a questionnaire combining open- and closed-ended questions was distributed to participants. The survey focused on (1) participants' expectations for the workshop; (2) workshop outcomes, highlights and weaknesses; and (3) ergonomics of the game and facilitation of the workshop.

In this section we present the general principles of the practical use of the method based on the four case studies and illustrate the method by further developing one of the case studies, which involved three dairy farmers from the mountainous Aubrac region of the Massif Central (France). Farming systems in Aubrac are mainly livestock systems located from 900-1300 m in elevation. From 19792009, average annual rainfall was $1400 \mathrm{~mm}$ and average annual effective rainfall was $700 \mathrm{~mm}$. Permanent and temporary grasslands including summer pastures cover more than $90 \%$ of farmland in the region, and most farmers are prohibited from feeding animals silage (grass or maize) due to their contractual agreements to conform to quality-label specifications. Full grazing is performed from May to November. Dairy herds in this area consist mainly of cows of the Simmental breed. In 2010, the average utilized agricultural area of a farm in Aubrac was 80 ha (Agreste, 2010).

None of the three farmers participated in all of the workshops (i.e. two farmers in each workshop). The workshops were held in March 2013, with W2 and W3 held on the same day. Each workshop required about two hours. They involved two facilitators who managed group dynamics and ensured that the workshops ran on time. One facilitator was in charge of real-time manipulation of the evaluation spreadsheet.

\subsection{Preparing the workshops}

The intermediary objects necessary for the workshops include material representing:

- the specific weather under study, using indicators familiar to farmers (charts of daily average temperature, four-week rainfall, daily soil moisture and daily herbage growth)

- the farm structure, its management and performance (game board, card representing herd management and feeding, forage sticks and evaluation spreadsheet)

- the impact of the specific weather scenario on forage resources (forage sticks).

Preferably, but not necessarily, the facilitators prepare the workshops. In our example, two research staffs prepared and facilitated the workshops.

The time needed to prepare the workshops depends on the number of climatic years and forage sticks considered. It is roughly one day per climatic year (when using 20 forage sticks) for a skilled person once the data have been gathered (i.e. weather data and scenario, grassland types, soil properties, farming practices). Thus, two days are needed to prepare $\mathrm{W} 1$, and one day each for W2 and W3. Each workshop lasts 2 hours.

\subsubsection{Choice and use of the weather scenarios}

Four weather scenarios are used in the FARMORE method, one representing past climate conditions and three representing future climate conditions, with a time horizon depending on the project. The weather data come either from past real data sets or from simulations of future climate (Table 2).

The annual weather series are presented to participants with three intermediary objects that are explained and discussed at the beginning of the workshop and then left on the game board. Three charts represent data from 1 January to 31 December:

- Chart 1: daily average temperature and available soil water in shallow and deep soils, which are two key factors for plant growth

- Chart 2: cumulative rainfall in four-week periods which can be used as an indicator of soil bearing capacity. Annual cumulative rainfall is also specified

- Chart 3: herbage growth profile of a grazed permanent grassland common in the study area that provides an overview of weather impact on herbage growth. One profile is provided for each weather scenario: current average (W1), future average (W1), and the two specific years under study (W2 and W3). 
The charts used for our case study are included in the supplementary material.

We constructed or selected the climatic years used during the workshops based on data from:

- a $12.5 \mathrm{~km} \times 12.5 \mathrm{~km}$ grid of weather data from 1980-2009 from Météo France for reference years

- climate simulations of the IPCC A1B SRES scenario by the ARPEGE-climate model (Déqué et al., 1994) that were statistically downscaled $(8 \times 8 \mathrm{~km})$ using the Boé method based on weather-typing (Pagé et al., 2008) for future years (2070-2100).

For W2 we chose a "favorable but challenging" climatic year with higher annual forage availability $(+19 \%)$, a later spring and an earlier summer and winter than the future average year. For W3, we chose an "unfavorable and infrequent" climatic year with lower annual forage availability (-48\%), an earlier spring and summer and a later winter than the future average year. More detailed information about the construction and characteristics of weather scenarios is provided in the supplementary material.

Table 2: Description of the climatic years used in the practical illustration of the method: climate dataset and weather scenario used, annual herbage surplus or excess compared the current average climatic year and general characteristics of the year used in each workshop

\section{Workshop 1 \\ Change in trend}

Workshop 2

Future variability (sample 1)
Workshop 3

Future variability (sample 2) and limited forecasting

$\begin{array}{ll}\text { Climate dataset } & \text { a. } 1980-2009 \text { weather data } \\ \text { Weather scenario } & \text { b. IPCC A1B SRES for 2070-2100 } \\ \text { Constructed average climatic year } \\ \text { from a. past data; b. projections }\end{array}$

IPCC A1B SRES for 2070-2100

IPCC A1B SRES for 2070-2100

Favorable but challenging climatic year

Unfavorable and infrequent climatic year

\section{Annual herbage surplus or \\ excess • \\ $\%$ difference compared the current average climatic \\ year}
$+53 \%$
$-33 \%$
b. $+27 \%$

Characteristics of the year

Average spring availability;

high fall herbage growth that is difficult to use due to high rainfall

Very long summer and herbage shortage in spring

-: according to seasonal-scale exposure indicators developed by Sautier et al. (2013b), calculated without changing the parameters and with the 1980-2009 reference period.

\subsubsection{Collection and use of information about local livestock systems}

Information about local grasslands, crop types, farming practices and soil properties is collected from farmers and extension agents to produce animal cards, diet cards, forage sticks and charts of daily available soil water tailored to the study area. Information about breeding type(s) and herdmanagement practices (e.g. calving practices, first calving age and production level - meat or milk) are used to produce animal cards. Information about plant-type composition and associated management practices (i.e. fertilization, irrigation, grazing management or cutting policy) are used together with climate scenarios (see below) to produce forage sticks. Soil available water capacity is used to produce both forage sticks and charts of daily available water (supplementary material). The information is collected by interviewing either an expert on local livestock farming systems or several local farmers about their own practices. For the current weather scenario (W1), forage sticks are developed using crop models; agricultural consultants and/or farmers can provide feedback about model predictions. For the future weather scenario (W1, W2, and W3), crop models should represent the stimulating effect of increased atmospheric carbon dioxide concentration on radiation-use efficiency.

In our example, information was collected by interviewing four Aubrac dairy farmers (three of them participated later in the workshops). The forage sticks were created by running simulations that responded to the chosen weather scenario and various strategies for the forage resource. Grasslands were simulated with the HerbSim model modified by Martin et al. (2011b). Radiation-use efficiency 
increased by $18 \%$ in simulations of future scenarios representing the carbon dioxide fertilization effect according to the Olioso et al. (2010) model for the Bern-CC model under the "high CO2" parameterization hypothesis (IPCC 2001). Details about the information collected about local livestock systems and the associated intermediary objects are provided in the supplementary material.

\subsection{Participatory design in action}

\subsubsection{Initial discussion to imagine options for testing}

At the beginning of $\mathrm{W} 1, \mathrm{~W} 2$, and $\mathrm{W} 3$ the facilitators present or remind participants of the overall objective of the method and the three-stage process. They indicate which stage they are in the workshop series and detail the workshop's goal, the tool used and its rules. Then, in W1, the facilitators present the game components and how to use them. In W2 and W3, the facilitators present the system designed during the last workshop and summarize the discussions that occurred. Finally, in W1 and W2, the facilitators present the climatic year under study.

Once the workshop is introduced, participants are invited to discuss which system or adaptation should be represented on the board. The discussion allows a group dynamic to be established, building trust among participants and between participants and facilitators. Participants can ask facilitators for explanations about the climate data and the charts. Facilitators and participants can ask about the motivations underlying any adaptation option suggested.

In W1, participants first have to agree on which system to represent for the current climate, which could be one suggested by a participant or a virtual one. This first collective decision is made under climatic and local constraints with which participants are very familiar. Participants then become comfortable when supporting ideas and explaining rationales for farming practices they might suggest. They only have to manage how a real system can be represented on the board. At this moment, the discussion allows participants to describe their own practices. In our example, participants chose to reproduce a typical farming system in the area.

When dealing with the future average climatic years (W1) or a sample of future climate conditions (W2), participants first discuss potential adaptations only by looking at the different climate charts, including the one representing the consequences for grass growth. The corresponding forage sticks and spreadsheet results are kept hidden. The board is not used at this stage.

In the four case studies, participants in W1 compared the future profile of grass growth to the current profile to suggest a change in grazing dates, to estimate hay requirements during summer or to determine whether hay production would be higher or lower than in the past. Frost, snow or weightbearing limitations were considered based on temperature, rainfall and soil water capacity charts.

\subsubsection{Implementing and evaluating design options}

Participants then implement and assess the adaptations selected on the game board. In our example, the spreadsheet allowed checking the amount of forage needed or in surplus for each period and at the end of the year. Depending on the result, tactical or strategic adaptations of the system were maintained or revised. The board and spreadsheet were used as a support for discussion when an adaptation was suggested or challenged.

In W2, implementing the adaptations allows participants to detail their strategy for the location of the herd on the grassland. The specific dates of grazing practices (i.e. start grazing, move the herd, end grazing) are roughly decided based on the indications of grass growth on the forage sticks. Participants used the spreadsheet to precisely set the grazing dates (usually one week before or after the intuited date). The weekly herbage surplus or shortage indicated by the spreadsheet often is used by growers to assess how much grazed area they can allow for hay (if excess of grass) or how much cut area they can move into grazing. The amount of grass excess or shortage at the annual level is used to change the number of animals if the tactical adaptations are not sufficient. Participants also monitor the amount of stocked forage they have during and at the end of the year to check if they need to buy hay during the year (if yes, participants discuss when and how much) or if the final amount of hay is acceptable to start another year. Weather charts are used to evaluate frost, snow and weight-bearing risks at the weekly level. 
In W3, the evaluation is performed for each 4-week period (before the future weather is disclosed). Participants test their ideas without formally discussing them. Successful ideas are then discussed to reach an agreement among participants. Unlike the other workshops, the choices are irreversible.

At the end of each workshop, participants perform a final evaluation of the designed system and its management. As a conclusion, participants are asked to summarize the decisions and discussions of the workshop as well as to raise challenges induced by the climatic year studied that were not explicitly considered by the spreadsheet.

\subsubsection{Trustworthiness of the manipulated information}

Throughout the entire process, participants discuss the validity of the information represented by the intermediary objects while designing a system: participants ask facilitators how data were collected and produced. Such a validity test is critical to earn the trust of participants about the tool and intermediary objects, the facilitator's scientific skills and credibility, and the entire method. The more accurate the information, the better. Discredit can be avoided if facilitators are able to locate the source of any error (e.g. lack of information, incorrect model calibration, unit error). Participants test the method's validity mostly in W1, when the current climatic year is considered. In it, participants can refer to their own references to assess the data represented by the intermediary objects. They can assess the forage sticks by examining the productivity and the seasonality represented (e.g. start of grass growth, grass growth peak, end of grass growth, and, for hay-oriented grasslands, harvest). They can assess the feeding requirement module by looking at (1) the agreement between the number of animals that can be fed and the area and type of grassland that is required to feed them and (2) the herbage surplus after grazing.

\subsection{Results of the design: suggested changes}

For the case study considered, participants designed a system for the current average climatic year by reproducing the general features of a typical system affiliated with the local milk and cheese cooperative, which ensures higher prices for milk provided some conditions are satisfied (no silage, and a minimum period of 120 grazing days): 70 ha of total farming area, 200,000 L of annual milk production from 40 dairy cows producing $5000 \mathrm{~L} /$ year, calving spread throughout the year and an age of first calving of 36 months. Land-use characteristics were designed by reproducing the participants' systems: $100 \%$ permanent grasslands, half grazed and half cut or grazed early and then cut. Hay stock at the beginning of the year (1 January) was 120 tons of dry matter, which correspond to 147 feeding days. The herd was divided into two herd subgroups: 40 dairy cows and 30 heifers. Grasslands were divided into six combinations of vegetation type $\times$ grazing or cutting management. The diet consisted of hay and grazing. Grazing started at the end of April and ended at the end of November, and full grazing occurred between mid-May and the beginning of November.

To cope with the future average climatic year, participants modified the size, land use and diet of the system. Adaptations to higher annual production included removing summer pastures (13 ha, i.e. $19 \%$ of the total area) and increasing the number of animals ( +17 animal units, i.e. $+28 \%$ of the initial number). Removing summer pastures was seen as decreasing the workload. These changes resulted in an increased stocking rate. Adaptations to changes in grass-growth dynamics included changing grazing management and the diet. Grazing started four weeks earlier and hay was distributed in July and August, whereas full grazing occurred between May and November in the reference system. The end of grazing did not change. Hay stock at the beginning of the year consequently decreased to 114 feeding days (still with 120 tons of dry matter).

In the case of the favorable but challenging climatic year, even though grass was available five weeks earlier than in the future average climatic year, grazing only started one week early because of high rainfall $(160 \mathrm{~mm} /$ month, implying low weight-bearing capacity, which prevents grazing). A part of the grasslands destined for cutting (7 of 23 ha, i.e. $30 \%$ of the cut area) was opened to early grazing (early enough to not remove the inflorescence) to compensate for low grass growth in April. Participants decided to increase the proportion of hay in the diet during May and July to cope with grass shortage during grazing. At the end of the year, the quantity of hay remained the same as the start of the year. 
The last workshop aims at adapting to an unfavorable and infrequent climatic year. The earlier start of growth compared to the future average climatic year led to grazing beginning one month earlier. The area of cut grasslands was decreased to increase the grazed area in response to the lower herbage growth from mid-March to mid-May. The lack of grass growth in June required adding hay to the dairy cow diet. In July, August and September, the lack of grass growth led to a diet composed only of hay for the two subgroups on the farm. In addition, it was impossible to graze cut grasslands after they were harvested, since low soil available water impeded growth, unlike during the average year. Participants had to buy 22 feeding days of hay to feed their animals during the final days of the year. This decision was made at the last moment, i.e. when there was no more stocked hay. They would have needed to buy a total of 136 feeding days to reach the same amount of stocked forage as at the end of the future average climatic year.

\section{Discussion}

\subsection{Outputs and outcomes of the method in our case study}

The adaptations are specific to grassland-based livestock systems in Aubrac; they experience less exposure to climate change than plain or plateau systems at lower elevations (Sautier et al., 2013b). Summer pastures were removed to adapt to future climate conditions defined by higher spring grass growth. Even though impacts of such changes beyond the farm level were not discussed in the workshops, we expect that they will be substantial. Fewer summer pastures could change the physical environment via spontaneous reforestation of mountainous areas (Sitzia et al., 2010). Major social, economic and cultural impacts are also expected. Summer pastures provide fodder for livestock, promote livestock products with labels of origin, are embedded within cultural events, benefit tourism and shape the local socioeconomic environment (López-Santiago et al., 2014).

Another adaptation the group tested was to increase the number of animals (while decreasing the land area). This increased herd feeding requirements and addressed the increase in forage production. However, it increased the system's sensitivity to adverse years in the future. Grasslandbased systems are especially prone to weather-related fodder shortages. Since shortages impact entire areas, farmers must buy fodder from remote areas at high costs. Participants considered the W3 situation as catastrophic since they had to buy the equivalent of $75 \%$ of the hay produced in an average year. They agreed that the situation was acceptable, however, since it was expected to occur only once every ten years. Farmers concluded that they should not have increased the number of animals as much as they did. However, they were concerned about practical implications of oversizing grasslands over animal needs (e.g. How does one maintain areas that are not necessary in average years?). Since the practice is uncommon at the farm level (Nettier et al., 2011), recommendations for managing understocked grassland-based livestock systems are not available.

Regarding tactical adaptations, participants extensively discussed decisions about when to start and end grazing. Currently, models are used before the workshops to construct the forage sticks, and evaluation is based on static balance calculations. This hinders adequate representation of consequences of strategic and tactical choices. For example, since impacts of stocking rate management on grass growth are not considered, the current intermediary objects might overestimate forage availability and thus underestimate the degree of adaptation needed. The method would gain realism and accuracy by representing dietary impacts on milk production, health risks, grazing management (e.g. starting and ending dates, grazing intensity) and grass growth and quality. This would help participants make tactical decisions based on quantitative considerations specific to the case considered. Knowing subsequent fodder costs would also provide useful information. Using simulation models in workshops (Rodriguez et al., 2014) might address this obstacle, but future investigation is needed to find a salient and legitimate way to do so. These models might increase the salience of the design and evaluation process, but they could simultaneously decrease its credibility. Simulation models, which participants do not necessarily perceive as valid, are difficult to understand. Participants struggle to trust such models since they cannot verify whether they are consistent with their knowledge.

The general increase in grass availability for the $2085 \pm 15$ time horizon and the A1B SRES scenario in the Aubrac region could explain why farmers tested only incremental adaptations. Although structural 
and production limitations in dairy systems (e.g. location of the milking parlor, few opportunities for suboptimal feeding) make them less flexible and potentially more sensitive to changes in the environment than beef systems, incremental adaptations were sufficient to address the climate in this situation, and no transformational adaptation was required. Such a positive climate change impact could be experienced in rainy and temperate areas, such as the mountainous Aubrac region, as long as the increasing water deficit does not cause problems. Climate change is accompanied by an increase in atmospheric carbon dioxide concentration and a longer growing season due to higher temperatures, which increases annual grass biomass production (Graux et al., 2013). Since incremental adaptations were sufficient, no transformational adaptations were tested, although they were alluded to in preliminary interviews (e.g. changing breeding practices, establishing irrigation or temporary grasslands). Our method could potentially support design of transformative adaptations in systems more exposed or sensitive to climate change, such as systems at lower elevations and/or that rely on rainfed maize (Ruget et al., 2010). More extensive changes are expected if participants are accustomed to managing non-perennial grasslands and can consider them an option, which opens up a variety of land-use configurations and management alternatives.

The method's success in fostering learning about climate change, its effects on livestock systems and potential adaptation options depends on participants' motivation to engage in the process. Since farmers might focus on short-term rather than long-term considerations, such as adaptation to climate change (Faysse et al., 2014), skilled facilitation is needed to maintain the motivation in these participatory-design processes. Facilitators manage group dynamics, ensuring that each participant has an equal opportunity to contribute and discuss design choices, reformulate main points, identify remaining issues and keep the workshops on time. They develop an expertise on factors that increase participants' involvement, learning and satisfaction. For example, the two facilitators involved in the four case studies reported that participants' involvement was higher when the farm studied was a typical farm of the area than when it was the farm of one of the participants. They also reported that during the three workshops and for the four case studies, the increased realism of the decisionmaking environment created new design challenges that stimulated participants' motivation. Participants were not overly eager to design new systems, but were curious about the extent of local climate change, its influences on forage resources and potential adaptation options to address them. Participants implicitly wanted to test whether their own farming systems were sufficiently robust to address the future climate. This behavior is consistent with their adaptation to pressures, which is based mainly on observation and feedback between actions and consequences (Feola and Binder, 2010). Using an assessment tool during workshops might have encouraged participants to evaluate their current strategies instead of designing and testing new strategies. Farmers seem more inclined to try new options when the participatory design workshop does not use assessment tools (e.g. Willaume et al., 2014). However, the evaluation spreadsheet was essential to differentiate each climatic year and its influence on forage resources and thus on the system's behavior. The sequential design method was a means to clearly communicate scientific information about climate change that was specific to participants' situations. Unsurprisingly, the farmers we contacted who did not participate in the workshops (four out of sixteen farmers) were the only climate-change deniers and remained uninterested, even when we presented the method as a way to imagine adaptations to address climate variability.

Participating in the workshops encouraged farmers to discuss the viability of real farming systems in the area under future climate conditions. The group of dairy farmers in Aubrac discussed the need to change quality-label specifications of livestock products to adapt to potentially fewer grazing days. They also discussed multiple consequences of not using summer pastures to both the dairy and beef industries. In the four case studies, the workshops encouraged participants to express their attitudes about risk, for example, through discussions about the need to buy hay, and if so, when and how much. Discussions elicited practical challenges of grazing management, such as managing diet shifts or the quality of pastures (not grazing when the soil is too wet) or hay (hay made after grazing has lower quality and is inadequate for productive animals). The last workshop (W3) was the participants' favorite because it closely resembled their day-to-day activities. Participants also indicated that understanding the interactive and informative supports and the game rules established in W3 would have not been possible without the two previous workshops. 


\subsection{Improved salience and credibility of the design process}

The method's well-defined sequences are the keystone that makes it more salient for adapting to climate change than other methods. It simultaneously and explicitly addresses climate change, climate variability and the limited predictability of weather. By definition, the method goes beyond current farming-design methods. Addressing climate change in farming-system design implies imagining systems adapted to climate conditions that have not yet occurred. Consequently, previous experience in managing current systems is of limited use (Rodriguez et al., 2014). Although several methods address one or two of these features, we are not aware of a method that includes all of them together. Participatory and non-participatory methods involving a simulation model address climate variability by simulating the system over several years (e.g. Crimp et al., 2008; De Trincheria et al., 2015; Rodriguez et al., 2014; Ruget et al., 2013). In most design methods, limitations are known in advance and an optimization algorithm generates the most suitable management options based on the model and criteria used. Occasionally, the limited predictability of weather is considered in simulation-based studies by parameterizing a decision module (see Crimp et al., 2008) or when participants choose a management practice based on a probabilistic representation of climate options and its impacts (De Trincheria et al., 2015). These approaches, however, do not include farmers in the decisional aspect of managing the system in the face of the limited predictability of weather.

The sequences are also key for placing participants in realistic management situations involving the limited predictability of weather and climate change in a way that fosters their creativity without overwhelming them with information. This increases the method's credibility, which is more transparent since participants determine the strategy and operational management of the farming system. In such methods, sufficiently refined temporal and spatial scales need to reflect the stocking rate and diet adjustments necessary to address climate variability. The refined temporal and spatial scales increase credibility because the design context is similar to the conditions farmers encounter each day.

In practice, effective design efforts must balance trade-offs among the salience, credibility, and legitimacy of scientific information or methods, and between the time necessary to conduct the participatory process and the participants' available time. Guiding the design through sequences of growing complexity increases the method's salience and credibility for designing adaptations to climate change. It also enables designing solutions that are more robust than those of existing participatory methods, since the system is (1) designed and tested against a sample of future climate variability (three years) instead of the average year used in classic methods and (2) designed at finer temporal and spatial scales, allowing for more accurate evaluation of system viability. This requires additional time because the sequencing requires conducting two additional workshops that must be attended for practical reasons: the three workshops are needed to reach the level of detail required to address climate variability and its low predictability. Increasing the realism of the design process by explicitly representing the spatial organization of plots, considering several successive years or specifying the socio-economic context, as performed by Lamarque et al. (2013), might increase attractiveness of the method. However, a trade-off exists between the sophistication of the design process and an acceptable duration of workshops.

Using three years may not be sufficient to design a system truly adapted to climate variability, since a climate comprises more than three normal climatic years (Sautier et al., 2013a). Participants could collectively choose climatic years before the workshops to maintain transparency of the process, reduce the shortcomings of this simplification and meet participant needs. Group selection would also increase motivation, since it considers participants' needs and interests.

\subsection{Practical and scientific challenges}

A fundamental principle underlying FARMORE and Forage Rummy is that rather than asking farmers to adopt ready-made agricultural innovations, research and extension would benefit from providing participatory design methods that allow farmers to develop their own adapted system. Martin (2015) identified challenges to improving Forage Rummy, which mainly entails improving the representation of uncertainty in the materials and computer objects and describing and analyzing research outcomes, such as farmers' learning. It is difficult to know to what extent FARMORE helps in increasing the adaptive capacity of participants, since this was not the focus of this study. Based on post-workshop surveys, we can say that seven of the twelve farmers reported that the workshops 
helped them to better understand climate change and its potential impact on their farms. Five of the seven reported this learning outcome only after W2 or W3, which shows the additional value of having the sequence of three workshops. Eight of the farmers reported that the workshops allowed them to identify possible adaptations in response to climate change. This provides an initial indication that the method helped increase farmers' awareness of climate change impacts and adaptation options, all of which contribute to adaptive capacity (Arbuckle et al., 2013; Marshall et al., 2013). The next step would be to assess more deeply the method's ability to improve farmers' adaptive capacities to climate change by combining interviews, surveys and participant observations to ensure data triangulation (see Sewell et al., 2014).

Based on the four case studies, we identified two additional challenges that have scientific and societal dimensions. The first relates to scaling up the method to expand the community of beneficiaries, while the second concerns the ability of FARMORE to fully integrate mechanisms underlying climate adaptation and mitigation through the provision of ecosystem services. Using FARMORE at a large scale is a major challenge in preparing livestock systems to address climate change. Extension agents have a privileged position for disseminating the method since they are a medium between research and the field. Their cooperation is paramount since climate change must be communicated through existing and functional networks of farmers rather than through climatespecific communication programs (Meinke et al., 2006). Experience with Forage Rummy reveals that extension agents are willing to engage in the method and use it with groups of farmers (30 extension agents have been trained, more than 200 farmers have participated and 60 game boards have been sold) (G Martin, pers. comm.). Similar to Forage Rummy, FARMORE requires a two-day training session for facilitators. It also requires one additional day to conduct two other workshops. Such requirements might prevent extension agents from widely disseminating the method and prevent farmers from participating. FARMORE facilitates farmers' learning about climate change and its influences on forage resources, and tests adaptations in only three half-days. Several measures can bridge the gap between the facilitators' workload and the participants' interest in the game. For example, involving participants in climate-year selection or presenting unexpected behaviors of systems designed in other pedoclimatic contexts can increase motivation at little cost.

A future challenge is to improve other participatory approaches in the spirit of FARMORE, such as by representing impacts of management practices on ecosystem services related to soil dynamics as for example soil quality, biological regulations and the stability of grassland production over several years (Sanderson, 2010). As a consequence, these services can decrease synthetic inputs (Bender et al., 2016). However, the current version of FARMORE is not equipped with appropriate knowledge of soilrelated processes. One way to integrate them would be to use soil-sensitive simulation models after participatory workshops. Post-workshop simulations would allow further examination of the consequences of management practices, which cannot occur in the limited time of the workshops. These additional simulation outputs and the potential to thoroughly test new climatic years would improve the creativity in decision making and problem solving. This improvement in the method enriches the reliability and depth of the evaluation process without changing the duration and userfriendliness of the workshop.

\section{Conclusions}

Designing with FARMORE is one way to iteratively revise a set of needs, limitations, goals and preferences to imagine a new grassland-centered livestock system defined by its material infrastructure (land-use, livestock and equipment configuration) and its intended use (management strategy). The solution is constructed incrementally and improved from one workshop to the next. Creation and selection of solutions is a continuous process in which the designer expands on suggestions and verifies compliance based on needs, limitations, goals and preferences. The designer controls the process and is free to design according to personal taste, style, abilities and beliefs. Designing a system with FARMORE entails developing and refining the formulation of the problem and ideas for a solution with constant iteration of analysis, synthesis and evaluation processes within and between workshops. As new insights occur, the designer may change certain goals and preferences to adopt alternatives, and new limitations may emerge. 
The FARMORE method structures the design problem and process by providing intermediary objects familiar to farmers and gradually introducing difficulties via three separate stages of the design process. Its success also stems from the realism of the problem addressed. To provide practical significance to the design, it is essential to place the designer in the context of a concrete problem, with limited ability to predict weather.

To generate salient and credible solutions, the participatory approach recognizes the importance of obtaining different types of knowledge and different perspectives. Scientists contribute through models, principles or prediction and farmers through local expertise and practical know-how. FARMORE helps clarify scientists' role in supporting the design process. Farmers are well aware of the general climate in their area, its variability, and impacts of this variability on forage production. However, their ability to discern long-term trends is more subjective and limited. Therefore, modelbased description of seasonal grass growth in various future climate scenarios is essential to determine how management pressure will change and the magnitude of impact requiring adaption. Scientists also have much to learn from farmers with their pertinent observations, experimentation and farming practices. In short, a participatory approach such as FARMORE promotes knowledge exchange rather than knowledge transfer.

FARMORE supports a learning-by-doing approach between workshops. Each workshop introduces new climate conditions and thus efforts to adapt to the climate's challenges. As such, FARMORE could also be used in agricultural education to increase students' awareness of potential impacts of climate change on seasonal productivity and to expose them to holistic thinking and systemic approaches, which are key abilities for addressing complex situations. In either setting, it would be beneficial to study in depth the conditions under which learning is most effective for individuals and the group and whether lessons can be adopted and transferred.

One positive result of applying the method is confirmation that options exist to adapt to climate change, at least one of moderate magnitude. Future research and development initiatives that consider climate variability along with climate change are needed to design robust, salient and credible adaptation options.

\section{ACKNOWLEDGMENTS}

This work was funded by the French National Institute for Agricultural Research, Metaprogramme Adaptation of agriculture and forests to climate change (ACCAF), through the project FARMATCH. We gratefully thank the farmers and the extension agents who participated in the study. We thank Romain Lardy and the two anonymous reviewers for comments and suggestions that greatly improved the manuscript.

\section{REFERENCES}

Agreste, 2010. Farm Accountancy Data Network [WWW Document]. URL https://stats.agriculture.gouv.fr/disar/ (accessed 3.3.16).

Arbuckle, J.G., Prokopy, L.S., Haigh, T., Hobbs, J., Knoot, T., Knutson, C., Loy, A., Mase, A.S., McGuire, J., Morton, L.W., Tyndall, J., Widhalm, M., 2013. Climate change beliefs, concerns, and attitudes toward adaptation and mitigation among farmers in the Midwestern United States. Clim. Change 117, 943-950. doi:10.1007/s10584-013-0707-6

Bartels, W.-L., Furman, C.A., Diehl, D.C., Royce, F.S., Dourte, D.R., Ortiz, B. V., Zierden, D.F., Irani, T.A., Fraisse, C.W., Jones, J.W., 2013. Warming up to climate change : a participatory approach to engaging with agricultural stakeholders in the Southeast US. Reg. Environ. Chang. 13, S45S55. doi:10.1007/s10113-012-0371-9

Bender, S.F., Wagg, C., van der Heijden, M.G., 2016. An underground revolution: Biodiversity and soil ecological engineering for agricultural sustainability. Trends Ecol. Evol. 31, 440-452. doi:10.1016/j.tree.2016.02.016

Cash, D.W., Clark, W.C., Alcock, F., Dickson, N.M., Eckley, N., Guston, D.H., Jäger, J., Mitchell, R.B., 2003. Knowledge systems for sustainable development. Proc. Natl. Acad. Sci. U. S. A. 100, 8086-91. doi:10.1073/pnas.1231332100 
Crimp, S., Gartmann, A., DeVoil, P., Gaydon, D., Howden, S.M., Odgers, J., 2008. Adapting Australian farming systems to climate change : a participatory approach. A report to the Australian Greenhouse Office.

De Trincheria, J., Craufurd, P., Harris, D., Mannke, F., Nyamangara, J., Rao, K.P.C., Leal Filho, W., 2015. Adapting Agriculture to Climate Change by Developing Promising Strategies Using Analogue Locations in Eastern and Southern Africa: A Systematic Approach to Develop Practical Solutions, in: Leal Filho, W., Esilaba, A.O., Rao, K.P.C., Sridhar, G. (Eds.), Adapting African Agriculture to Climate Change, Climate Change Management. Springer International Publishing, pp. 1-23. doi:10.1007/978-3-319-13000-2

Déqué, M., Dreventon, C., Braun, A., Cariolle, D., 1994. The ARPEGE/IFS atmosphere model: a contribution to the French community climate modelling. Clim. Dyn. 10, 249-266. doi:10.1007/BF00208992

Duru, M., Therond, O., Fares, M., 2015. Designing agroecological transitions; A review. Agron. Sustain. Dev. 1237-1257. doi:10.1007/s13593-015-0318-x

Estrada, F., Gay, C., Conde, C., 2011. A methodology for the risk assessment of climate variability and change under uncertainty. A case study: coffee production in Veracruz, Mexico. Clim. Change 113, 455-479. doi:10.1007/s10584-011-0353-9

Faysse, N., Rinaudo, J.-D., Bento, S., Richard-Ferroudji, A., Errahj, M., Varanda, M., Imache, A., Dionnet, M., Rollin, D., Garin, P., Kuper, M., Maton, L., Montginoul, M., 2014. Participatory analysis for adaptation to climate change in Mediterranean agricultural systems: possible choices in process design. Reg. Environ. Chang. 14, 57-70. doi:10.1007/s10113-012-0362-x

Fazey, I., Fazey, J.A., Salisbury, J.G., Lindenmayer, D.B., Dovers, S., 2006. The nature and role of experiential knowledge for environmental conservation. Environ. Conserv. 33, 1. doi:10.1017/S037689290600275X

Feola, G., Binder, C.R., 2010. Towards an improved understanding of farmers' behaviour: The integrative agent-centred (IAC) framework. Ecol. Econ. 69, 2323-2333. doi:10.1016/j.ecolecon.2010.07.023

Graux, A.-I., Bellocchi, G., Lardy, R., Soussana, J.-F., 2013. Ensemble modelling of climate change risks and opportunities for managed grasslands in France. Agric. For. Meteorol. 170, 114-131. doi:10.1016/j.agrformet.2012.06.010

IPCC, 2001. Appendix I SRES Tables, in: Houghton, J.T., Ding, Y., D.J.Griggs, Noguer, M., van der Linden, P.J., Dai, X., Maskell, K., Johnson, C.A. (Eds.), Climate Change 2001: The Scientific Basis. Contribution of Working Group I to the Third Assessment Report of the Intergovernmental Panel on Climate Change. Cambridge University Press, Cambridge, United Kingdom and New York, NY, USA, p. 881.

Lamarque, P., Artaux, A., Barnaud, C., Dobremez, L., Nettier, B., Lavorel, S., 2013. Taking into account farmers' decision making to map fine-scale land management adaptation to climate and socio-economic scenarios. Landsc. Urban Plan. 119, 147-157. doi:10.1016/j.landurbplan.2013.07.012

López-Santiago, C.A., Oteros-Rozas, E., Martín-López, B., Plieninger, T., Martín, E.G., González, J. a., 2014. Using visual stimuli to explore the social perceptions of ecosystem services in cultural landscapes: The case of transhumance in Mediterranean Spain. Ecol. Soc. 19, 27. doi:10.5751/ES-06401-190227

Marshall, N.A., Park, S., Howden, S.M., Dowd, A.B., Jakku, E.S., 2013. Climate change awareness is associated with enhanced adaptive capacity. Agric. Syst. 117, 30-34. doi:10.1016/j.agsy.2013.01.003

Martin, G., 2015. A conceptual framework to support adaptation of farming systems - Development and application with Forage Rummy. Agric. Syst. 132, 52-61. doi:10.1016/j.agsy.2014.08.013

Martin, G., Felten, B., Duru, M., 2011a. Forage rummy: A game to support the participatory design of adapted livestock systems. Environ. Model. Softw. 26, 1442-1453.

doi:10.1016/j.envsoft.2011.08.013 
Martin, G., Martin-Clouaire, R., Rellier, J.-P., Duru, M., 2011b. A simulation framework for the design of grassland-based beef-cattle farms. Environ. Model. Softw. 26, 371-385. doi:10.1016/j.envsoft.2010.10.002

Meinke, H., Nelson, R., Kokic, P., Stone, R., Selvaraju, R., Baethgen, W., 2006. Actionable climate knowledge: from analysis to synthesis. Clim. Res. 33, 101-110. doi:10.3354/cr033101

Nettier, B., Dobremez, L., Coussy, J.-L., Romagny, T., 2011. Attitudes of livestock farmers and sensitivity of livestock farming systems to drought conditions in the French Alps. Rev. géographie Alp. 1, 1-11. doi:10.4000/rga.1307

Olioso, A., Huard, F., Guilioni, L., 2010. Prise en compte du CO2 dans le calcul de l'évapotranspiration de référence, in: Présentation Des Méthodes et Des Résultats Du Projet CLIMATOR. Versailles, France, pp. 66-67.

Pagé, C., Terray, L., Boé, J., 2008. Projections climatiques à échelle fine sur la France pour le 21ème siècle: les scénarii SCRATCH08. Toulouse.

Piquet, M., Frappat, B., Gin, P., Morel, K., Sautier, M., Duru, M., Moreau, J.-C., Martin, G., 2013. S'adapter ensemble (éleveurs, conseillers, chercheurs) au changement climatique: enjeux et exemple du Rami fourrager ${ }^{\circledR}$. Fourrages 215, 247-256.

Rodriguez, D., Cox, H., DeVoil, P., Power, B., 2014. A participatory whole farm modelling approach to understand impacts and increase preparedness to climate change in Australia. Agric. Syst. 126, 50-61. doi:10.1016/j.agsy.2013.04.003

Rodriguez, D., DeVoil, P., Power, B., Cox, H., Crimp, S., Meinke, H., 2011. The intrinsic plasticity of farm businesses and their resilience to change. An Australian example. F. Crop. Res. 124, 157170. doi:10.1016/j.fcr.2011.02.012

Ruget, F., Durand, J., Ripoche, D., Graux, A., Bernard, F., Lacroix, B., Moreau, J., 2013. Impacts des changements climatiques sur les productions de fourrages (prairies, luzerne, maïs) : variabilité selon les régions et les saisons 99-109.

Ruget, F., Moreau, J., Ferrand, M., Poisson, S., Gate, P., Lacroix, B., Lorgeou, J., Cloppet, E., Souverain, F., 2010. Describing the possible climate changes in France and some examples of their effects on main crops used in livestock systems. Adv. Sci. Res. 4, 99-104. doi:10.5194/asr4-99-2010

Sanderson, M.A., 2010. Stability of production and plant species diversity in managed grasslands: A retrospective study. Basic Appl. Ecol. 11, 216-224. doi:10.1016/j.baae.2009.08.002

Sautier, M., 2013. Outiller l'adaptation des élevages herbagers au changement climatique : de l'analyse de la vulnérabilité à la conception participative de systèmes d'élevage. Ph.D. Dissertation, Université de Toulouse.

Sautier, M., Duru, M., Martin-Clouaire, R., 2013a. Use of productivity-defined indicators to assess exposure of grassland-based livestock systems to climate change and variability. Crop Pasture Sci. 64, 641. doi:10.1071/CP13076

Sautier, M., Martin-Clouaire, R., Faivre, R., Duru, M., 2013b. Assessing climatic exposure of grassland-based livestock systems with seasonal-scale indicators. Clim. Change 120, 341-355. doi:10.1007/s10584-013-0808-2

Seneviratne, S.I., Nicholls, N., Easterling, D., Goodess, C.M., Kanae, S., Kossin, J., Luo, Y., Marengo, J., Mclnnes, K., Rahimi, M., Reichstein, M., Sorteberg, A., Vera, C., Zhang, X., 2012. Changes in climate extremes and their impacts on the natural physical environment. In: Managing the Risks of Extreme Events and Disasters to Advance Climate Change Adaptation, in: Field, C.B., Barros, V., Stocker, T.F., Qin, D., Dokken, D.J., Ebi, K.L., Mastrandrea, M.D., Mach, K.J., Plattner, G.-K., Allen, S.K., Tignor, M., Midgley, P.M. (Eds.), A Special Report of Working Groups I and II of the Intergovernmental Panel on Climate Change (IPCC). Cambridge University Press, Cambridge, UK, and New York, NY, USA, pp. 109-230.

Sewell, A.M., Gray, D.I., Blair, H.T., Kemp, P.D., Kenyon, P.R., Morris, S.T., Wood, B.A., 2014. Hatching new ideas about herb pastures: Learning together in a community of New Zealand farmers and agricultural scientists. Agric. Syst. 125, 63-73. doi:10.1016/j.agsy.2013.12.002 
Sitzia, T., Semenzato, P., Trentanovi, G., 2010. Natural reforestation is changing spatial patterns of rural mountain and hill landscapes: A global overview. For. Ecol. Manage. 259, 1354-1362. doi:10.1016/j.foreco.2010.01.048

Smit, B., Burton, I., Klein, R.J.T., Wandel, J., 2000. An anatomy of adaptation to climate change and variability. Clim. Change 45, 223-251. doi:10.1023/A:1005661622966

Thornton, P.K., Ericksen, P.J., Herrero, M., Challinor, A.J., 2014. Climate variability and vulnerability to climate change: A review. Glob. Chang. Biol. 20, 3313-3328. doi:10.1111/gcb.12581

Voinov, A., Bousquet, F., 2010. Modelling with stakeholders. Environ. Model. Softw. 25, 1268-1281. doi:10.1016/j.envsoft.2010.03.007

Willaume, M., Rollin, A., Casagrande, M., 2014. Farmers in southwestern France think that their arable cropping systems are already adapted to face climate change. Reg. Environ. Chang. 14, 333-345. doi:10.1007/s10113-013-0496-5 